\title{
SCANNING FORCE MICROSCOPY ON LASER ABLATED SILICON NITRIDE FILMS
}

\author{
C. Vrînceanu, C. Flueraru \\ Institute of Microtechnology, P.O. Box 38-160, Bucharest 72225, Romania
}

M. DINESCU

Institute of Atomic Physics, P.O. Box MG-6, Bucharest 76900, Romania

AND E. VASILE

METAV S.A., Zapada Mieilor 16-18, Bucharest 71529, Romania

The following paper presents a study on laser-ablated silicon nitride films, obtained by the laser reactive ablation method. The aim of this paper is to investigate silicon nitride film surfaces, first by scanning electron microscopy and then, at a better resolution and a greater magnification, by the scanning (atomic) force microscopy technique.

PACS numbers: 68.55.Jk, 61.16.Ch, 61.16.Bg

\section{Introduction}

Silicon nitride insulators are gaining increased interest and are being widely used for passivation, annealing masks and as a dielectric in metal-nitride-oxidesemiconductor (MNOS) structures for non-volatile memories.

Silicon nitride films can be prepared by reactive plasma deposition (RPD), plasma-enhanced chemical vapour deposition (PECVD) or by low pressure chemical vapour deposition (LPCVD). Recently, new laser-based methods have been developed, such as: pulsed laser deposition (PLD), laser chemical vapour deposition (LCVD) and laser direct synthesis (LDS).

For the present study, silicon nitride films were deposited by the laser reactive ablation (LRA) method. The laser reactive ablation method is derived from the pulsed laser deposition technique. PLD is used to deposit stoichiometric thin films of alloys or compounds by ablating already-prepared solid targets. Unlike PLD, in LRA, ablation occurs in a reactive gas atmosphere [1]. Thus, a solid target consisting of the material to be reacted is ablated in a reactive gas atmosphere. The resulting material is collected on a substrate placed at a given distance from the target [2]. Laser reactive ablation (LRA) is a new method, which combines (in one step) the synthesis of the compound and the deposition. The LRA method is 
highly successful, because it involves high purity (very low level of contamination), low thermal budget and versatility.

Silicon nitride films prepared in this way result in the formation of small surface polycrystalline zones, referred to as droplets. The goal of this paper is to study the surface's morphology and to establish a correlation between the droplets appearance and experimental conditions.

\section{Experimental details}

In this paper the laser reactive ablation method was used for the deposition of silicon nitride layers on silicon wafers by ablation of a silicon target in a $\mathrm{NH}_{3}$ environment. The experimental setup is made up of an excimer laser, type Lambda Physik LPX 315, operating with $\mathrm{XeCl}^{*}$ active mixture $(\lambda=308 \mathrm{~nm}$ and pulse duration-full width at half maximum $-\tau=30 \mathrm{~ns}$ ); depositions were made at repetition rates of $10 \mathrm{~Hz}$.

The targets with dimensions of $15 \times 15 \mathrm{~mm}^{2}$, were cut from silicon wafers. During irradiation the targets mounted on a holder were rotated at $3 \mathrm{IIz}$, in order to avoid the formation of deep craters which modify materials ejection characteristics. Laser irradiation falls on the target's surface at an angle of $45^{\circ}$ and the beam was focused on the surface with a Suprasil lens. The ablated material was collected on a silicon wafer mounted on the holder which could be heated with an electrical heater. During deposition the collector was heated at $200^{\circ} \mathrm{C}$. Both target and collector are $p\langle 100\rangle$-type silicon wafers. The laser fluency on the surface of the targets was in the range $5-6 \mathrm{~J} / \mathrm{cm}^{2}$.

This paper presents a study on four types of silicon nitride samples, prepared at two different target-collector distances (Table I). Each sample was prepared by collecting the material ablated by 10,000 laser pulses.

TABLE I

Silicon nitride samples investigated by scanning electron microscopy and atomic force microscopy.

\begin{tabular}{l|c|c|c}
\hline \hline Sample & $\begin{array}{c}\text { Ammonia } \\
\text { pressure [Tr] }\end{array}$ & $\begin{array}{c}\text { Deposited film } \\
\text { thickness [mm] }\end{array}$ & $\begin{array}{c}\text { Target-collector } \\
\text { distance } d[\mathrm{~mm}]\end{array}$ \\
\hline $\mathrm{SiN}_{1}$ & 1 & 2 & 14 \\
$\mathrm{SiN}_{2}$ & $5 \times 10^{-2}$ & 0.5 & 14 \\
$\mathrm{SiN}_{3}$ & $10^{-3}$ & 0.7 & 21 \\
$\mathrm{SiN}_{4}$ & $5 \times 10^{-2}$ & $0.15-0.4$ & 21
\end{tabular}

The morphological study of silicon nitride layers was performed by scanning electron microscopy (SEM) using a Philips SEM 515 microscope at a $20 \mathrm{kV}$ voltage and a magnification of $\times 1200$, and by atomic force microscopy (AFM) using a system constructed by the Department of Applied Physics, University of Twente [3].

The AFM system is made up of three main parts: the measuring head, hardware and software. The measuring head includes the cantilever with its support, 
an optical detection system for cantilever deflection measurements and a preamplifier. In this system the sample is fixed and the cantilever with tip is scanned with a piezo-tube $x y z$ translator. The hardware includes three high-voltage amplifiers, a scan control module and signal-selection and filter modules. The software was designed for maximal flexibility in an open structure. The software programme compensates for scanner nonlinearities with a third order polynomial. In this way the scan linearization reduces the nonlinearity in the AFM images from $40 \%$ to $1 \%$.

The AFM system operates by measuring the forces between the probe and sample. These forces depend on the nature of the sample, the distance between the probe and sample, the probe geometry and any contamination on the sample surface [4].

The measurements were done in air, in contact mode. A variety of sample regions of samples with maximum scan area $20 \times 20 \mu \mathrm{m}^{2}$ were investigated.

\section{Results and discussion}

The properties of the deposited films strongly depend on the phenomena which take place during the interaction of the laser pulse with the target. The process may be divided into the following steps: surface heating and váporization of the target, plasma generation, and subsequent material ejection under a reactive gas, leading to thin-film growth.

Scanning electron microscopy and atomic force microscopy are two methods which allow the investigation of surface layers. From both SEM and AFM micrographs we notice that the surfaces of all four samples exhibit some drop-shaped irregularities, called, in the literature [5], droplets.

In addition to atomic and molecular species these macroscopic droplet particles $(0.5-10 \mu \mathrm{m}$ in size) are ejected from laser ablated targets which degrade the surface morphology of the deposited layers. These particles, consisting mainly of spherical grains are very well characterized by SEM at a range of magnifications, and in particular at $\times 1200$ (Fig. 1). Surface droplet formation is believed to be related to the ejection of liquid material as droplets from the molten zone of the irradiated area which solidify upon arrival onto the substrate.

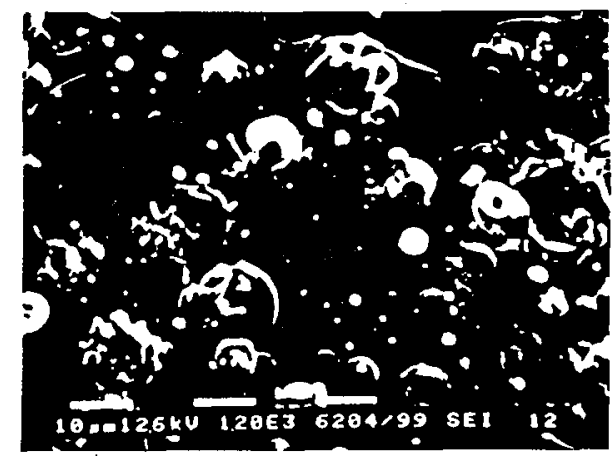

Fig. 1. SEM micrograph of $\mathrm{SiN}_{4}$ surface at a magnification of $\times 1200$. 


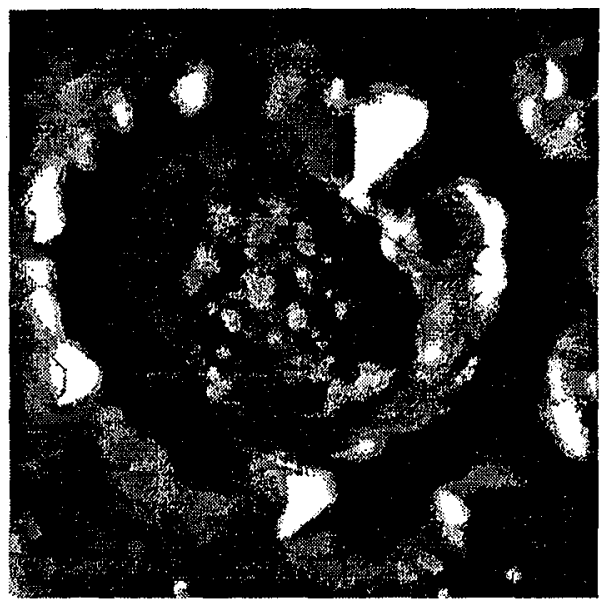

Fig. 2. AFM - plane view image inside one droplet $\left(\mathrm{SiN}_{4}\right.$ sample).

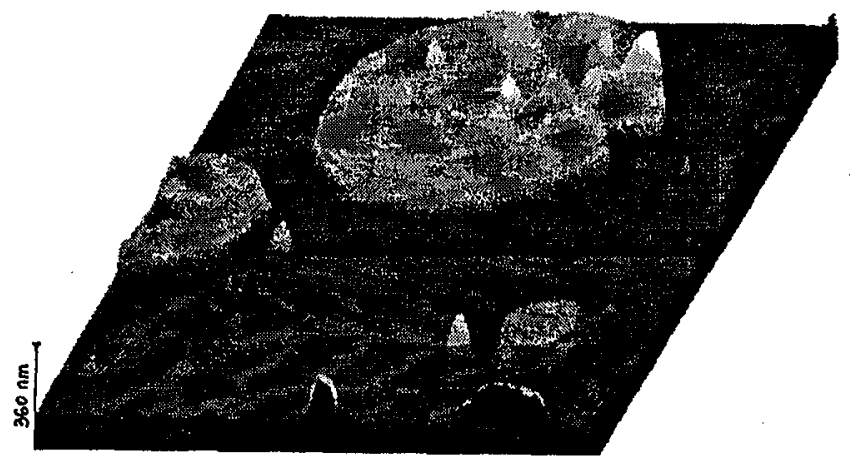

Fig. 3. AFM - 3D image of surface $\left(\mathrm{SiN}_{4}\right.$ sample).

Transmission electron microscopy (TEM) correlated with selected area electron diffraction (SAED) measurements show that these droplets are polysilicon [1]. A possible explanation of their appearance is the following: the nitridation reaction occurs on the collecting surface $\left(\mathrm{Si}_{3} \mathrm{~N}_{4}\right.$ does not exist in molecule form which could travel through to the surface as an individual molecule; $\mathrm{Si}_{3} \mathrm{~N}_{4}$ can only exist in condensed phase). The ablated material falling on the collecting surface consists not only of ions and atoms, but also of silicon clusters and droplets which could not be completely nitrided.

Unlike scanning electron microscopy which allows surface study up to a maximum magnification of $\times 20,000$, scanning force microscopy provides better resolution and greater magnification. Thus, AFM images allow us to investigate the droplets' morphology.

With regard to the four silicon nitride samples, presented in Table I, we note that for the same distance, the film thickness depends on the pressure, particularly 
if it varies strongly (namely $2 \mu \mathrm{m}$ for $\mathrm{SiN}_{1}$ and $0.5 \mu \mathrm{m}$ for $\operatorname{SiN}_{2}$, at $p_{\mathrm{NH}_{3}}=1 \mathrm{Tr}$, respectively $p_{\mathrm{NH}_{3}}=5 \times 10^{-2} \mathrm{Tr}$ ), and it is almost the same, if the pressure does not vary too much $\left(0.7 \mathrm{~mm}\right.$ for $\mathrm{SiN}_{3}$ and around $0.4 \mathrm{~mm}$ for $\mathrm{SiN}_{4}$, at $p_{\mathrm{NH}_{3}}=10^{-3} \mathrm{Tr}$, respectively $\left.p_{\mathrm{NH}_{3}}=5 \times 10^{-2} \mathrm{Tr}\right)[1]$.

TABLE II

Surface chararacterization of silicon nitride films by scanning electron microscopy and atomic force microscopy.

\begin{tabular}{|c|c|c|}
\hline Sample & Droplets' size determined by SEM & AFM investigations \\
\hline$\overline{\mathrm{SiN}_{1}}$ & $\begin{array}{l}7.25 \mu \mathrm{m} \text { - droplets have irregular } \\
\text { shapes }\end{array}$ & the layer presents a rough surface \\
\hline $\mathrm{SiN}_{2}$ & $\begin{array}{l}7.25 \mu \mathrm{m}-\text { droplets look as they } \\
\text { are "frozen" immediately in the } \\
\text { contact moment }\end{array}$ & $\begin{array}{l}\text { the layer presents a flat surface } \\
\text { with droplets from place to place }\end{array}$ \\
\hline $\mathrm{SiN}_{3}$ & $\begin{array}{l}6.6 \mu \mathrm{m}-\text { a lot of droplets with } \\
\text { a round shape; few of them are } \\
\text { irregular }\end{array}$ & $\begin{array}{l}\text { the droplets look as they are } \\
\text { melted and spread or like many } \\
\text { drops united }\end{array}$ \\
\hline $\mathrm{SiN}_{4}$ & $\begin{array}{l}6.5 \mu \mathrm{m}-\text { almost all droplets have } \\
\text { round shapes; it is a surface with } \\
\text { few droplets }\end{array}$ & $\begin{array}{l}\text { the polycrystalline structure of } \\
\text { silicon droplet with grain size be- } \\
\text { tween } 0.3-0.6 \mu \mathrm{m} \text { can be very well } \\
\text { seen }\end{array}$ \\
\hline
\end{tabular}

From the AFM images, plane view (Fig. 2 with a scan area of $3.5 \times 3.5 \mu \mathrm{m}^{2}$ ) and 3D (Fig. 3 with a scan area of $9 \times 9 \mu \mathrm{m}^{2}$ ), it can be seen that for $\mathrm{SiN}_{1}$ the silicon nitride layer appears rough, because of the successively deposited droplets, unlike the $\mathrm{SiN}_{2}$ sample, which is thinner and exhibits droplets only at the surface.

For the other two samples, $\mathrm{SiN}_{3}$ and $\mathrm{SiN}_{4}$, prepared at the same distance, $21 \mathrm{~mm}$, having almost the same thickness, the AFM study shows a flat surface with only occasional droplets. Unlike $\mathrm{SiN}_{3}$, where the droplets are overlapping, or look as a drop melted and spread, for $\mathrm{SiN}_{4}$ the drop shape is apparent, with a deepened center - where it hits the surface - and the edges reflected (see Fig. 2 and 3). Both $\mathrm{SiN}_{3}$ and $\mathrm{SiN}_{4}$ samples show the same polycrystalline structure inside one silicon droplet, in good agreement to TEM studies [1].

Table II presents the features of the surface investigated by scanning electron microscopy and atomic force microscopy.

\section{Conclusions}

We have shown that scanning force microscopy is an excellent technique for surface studies which complements results obtained with other characterization methods, such as transmission electron microscopy and X-ray diffraction. With it, we are able to characterize the silicon droplets' morphology, with a deepened polycrystalline center and spread borders. Also we note that for the same distance the droplets' size does not vary with the ammonia pressure, but decreases with increasing distance. 


\section{References}

[1] M. Dinescu, N. Chitica, V.S. Teodorescu, A. Lita, A. Luches, M. Martino, A. Perrone, M. Gartner, Laser Processing: Surface Treatment and Film Deposition, Eds. J. Mazumder, O. Coude, Kluwer Academic Publ., Dordrecht 1996, p. 809.

[2] A. Luches, G. Leggieri, M. Martino, A. Perrone, G. Majni, P. Mengucci, I.N. Mihailescu, Appl. Surf. Sci. 79/80, 244 (1994).

[3] K.O. van der Werf, C.A.J. Putman, B.G. de Grooth, F.B. Segerink, E.H. Schipper, N.F. van Hulst, J. Greve, Rev. Sci. Instrum. 64, 2892 (1993).

[4] C. Flueraru, D. Dascalu, Rom. J. Phys. 41, 295 (1996).

[5] E. Fogarassy, C. Fuchs, A. Slaoui, S. de Unamuno, J.P. Stoquert, W. Marine, B. Lang, J. Appl. Phys. 76, 2612 (1994). 